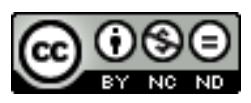

Revista Pax Domini é licenciada sob uma Licença Creative Commons.

\title{
A IMPORTÂNCIA DO SERMÃO EXPOSITIVO NAS ASSEMBLEIAS DE DEUS NO BRASIL
}

Douglas do Amaral Castro*

\begin{abstract}
Resumo
A presente pesquisa busca estudar a importância da pregação expositiva nas Assembleias de Deus no Brasil. Primeiramente, será abordado sobre a pregação expositiva e a sua relevância na arte da pregação, levando em consideração o seu conceito. Em seguida, verifica-se se houve um caminho ou descaminho da pregação expositiva na História das Assembleias de Deus do Brasil. Discorrendo um sucinto histórico oriundo de seus fundadores suecos, mostrando de que maneira a cosmovisão dos fundadores influenciou na pregação pentecostal. Finalmente, são apresentadas possíveis contribuições da pregação expositiva nas Assembleias de Deus no Brasil.
\end{abstract}

\section{Palavras-Chave}

Pentecostalismo, Assembleia de Deus, Pregação Expositiva.

\begin{abstract}
The present research is concerned with studying the importance of expository preaching in Assemblies of God in Brazil. Firstly, it will be approached about the expository preaching and its relevance in the art of preaching, taking into account the concept and its importance in the main periods of the History of the Christian Church. Next, it is verified if there was a way or way of the expository preaching in the History of the Assemblies of God of Brazil. Discussing a succinct historical from its Swedish founders, showing how the founders' worldview influenced Pentecostal preaching. Finally, possible contributions of the expository preaching in the Assemblies of God in Brazil are presented.
\end{abstract}

\section{key words}

Pentecostalism, Assembly of God, Expository Preaching.

*Graduado em Ciências Teológicas pela FBN; Graduado em Pedagogia pela UNIPAC; Pós-graduado em Psicopedagogia pela FGD. Email: pr.douglas04@gmail.com

Revista Pax Domini | Faculdade Boas Novas | v. 2 | p. 16 - 30 | mar. 2017 


\section{INTRODUÇÃO}

A comunicação na homilética, ou seja, na pregação nos fornece orientações divinas que nos auxiliará no jogo da vida, determinando a vitória ou a derrota eterna.

Sendo assim, em linhas gerais, o presente trabalho se preocupa em estudar quais os efeitos e contribuições da aplicação do Sermão Expositivo nas Assembleias de Deus do Brasil.

Em outras palavras, esta pesquisa objetiva estudar o contexto das igrejas pentecostais, devido aos indícios na história da existência de um anti-intelectualismo bíblico e teológico. O resultado disso pode ser percebido em pregações superficiais, desprovidas de uma interpretação correta das Escrituras. Entretanto, este labor teológico, em um primeiro momento, irá apresentar a definição de pregação, origem e significado da homilética, as três formas principais de sermão. Posteriormente, buscou-se averiguar, através da história das Assembleias de Deus do Brasil, se houve ou não a utilização da pregação expositiva. Finalmente, serão elencadas as possíveis contribuições da pregação expositiva para as Assembleias de Deus do Brasil.

\section{O SERMÃO EXPOSITIVO E A SUA IMPORTÂNCIA NA ARTE DA PREGAÇÃO}

Para compreender 0 desenvolvimento da pregação expositiva devemos compreender, porém, o que ela significa. A palavra "exposição" deriva do termo latino expositivo, que significa "divulgar, publicar" ou "tornar acessível". Observe que o sermão expositivo é um sermão que extrai uma mensagem da Escritura e torna acessível aos ouvintes contemporâneos. A maioria dos pregadores, segundo demonstrado na história cristã, usou da exposição bíblica. A pregação expositiva parece ter sido o estilo mais frequente de sermão e é apresentado por muitos teólogos e exegetas como o melhor meio de propagar a integralidade e a fidelidade da Palavra de Deus.

Desta forma, a qualidade espiritual do cristão e da Igreja depende da Palavra de Deus e a pregação, o ensino da mesma torna-se a parte mais relevante do serviço prestado a Deus. A igreja contemporânea vive com patologias ${ }^{1}$ internas, pois, muitos

\footnotetext{
${ }^{1}$ Patologia estudo de doenças e alterações que provocam doença no organismo.
}

Revista Pax Domini | Faculdade Boas Novas | v. 2 | p. 16 - 30 | mar. 2017 
pastores abandonaram o compromisso com a fé verdadeira. Outros pastores e líderes conservadores mantêm a fidelidade, mas sem produtividade.

No entanto, se alguém ler a bíblia ou se familiarizar com os principais acontecimentos da história da Igreja cristã, irá entender que as ações de Deus no mundo e a pregação estão intimamente ligadas. Em seu livro, Olyott ${ }^{2}$ descreve "que o Reino de Deus e a pregação são irmãos siameses que não podem ser separados".

Diante desta afirmativa, definir a pregação não é uma tarefa fácil. Contudo, está aqui a definição de Stott $^{3}$ "expor as Escrituras é esclarecer o texto inspirado com a tal fidelidade e sensibilidade que a voz de Deus seja ouvida e seu povo the obedeça". Porém, notam-se quão poucas pessoas são capazes de apresentar uma resposta satisfatória a esta questão. Portanto, considere-se estas quatro palavras gregas (Kerusso, Euangelizo, Martureo, Didasko) e de que forma elas nos ajudam a compreender o que é de fato pregação. A palavra grega Kerusso significa "declarar, como o faz um arauto". Segundo Olyott, a palavra Kerusso refere-se:

[...] à mensagem de um rei. Quando soberano tinha uma mensagem para os seus súditos, ele a entregava aos arautos. Estes a transmitiam às pessoas sem mudála ou corrigi-la. Simplesmente, transmitiam a mensagem que Ihes havia sido entregue. Os ouvintes sabiam que estavam recebendo uma proclamação oficial ${ }^{4}$.

Desse modo, este verbo é utilizado para enfatizar que o pregador não deve anunciar a sua própria mensagem. O pregador não propaga com sua própria autoridade. Ele foi enviado e fala com a autoridade de quem o enviou. Logo, a palavra grega euangelizo significa "trazer boas noticias" ou "anunciar boas-novas". Desta palavra originou-se a palavra evangelizar. Faz-se necessário salientar que kerusso e euangelizo não significam algo totalmente distinto. Da mesma forma a palavra grega martuero, este verbo significa "dar testemunho dos fatos", a contar as pessoas fatos e acontecimentos na íntegra. Por exemplo, em 1 João 1.2, o apóstolo empregou a palavra martuero ("damos testemunho"), ele falava do que vira e ouvira.

${ }^{2}$ OLYOTT, Stuart. Pregação pura e simples. 1. ed. São José dos Campos, SP: Editora Fiel, 2008, p.13.

${ }^{3}$ STOTT, 1999 apud LOPES, Hernandes dias. A importância da pregação expositiva para o crescimento da igreja. 2. ed. São Paulo: Editora Candeia, 2007, p.27.

${ }^{4}$ OLYOTT, Stuart, 2008, p.14.

Revista Pax Domini | Faculdade Boas Novas | v. 2 | p. 16 - 30 | mar. 2017 
Aprende-se que estas palavras não são divorciadas uma das outras, quando uso a palavra grega Kerusso ("pregar"), também estou praticando o euangelizo ("evangelizar"), através do martureo ("dar testemunhos dos fatos"), que resulta em didasko, a quarta palavra grega à qual veremos a seguir. A palavra grega didasko significa "ensino, doutrina". No entanto, o emprego desta palavra grega disdako não deve ser um simples acréscimo na pregação, deve ser na totalidade a mensagem em que é propagada. Isto pode ser observado em Atos 5.425, "os apóstolos não cessavam de ensinar (didasko) e pregar (euangelizo)".

Entretanto, o termo homilética vem do grego, omiletikós, "sociável". O verbo omileein, significa estar em companhia de; e o substantivo omilos significa assembleia. Visto que esse título homilética, refere-se aquele ramo da retórica que trata da composição e entrega de sermões. Assim, homilética é a ciência que se ocupa a pregação cristã, com a pregação proferida no culto, no seio da comunidade reunida. É importante afirmar que a homilética é auxiliada por duas disciplinas denominadas, hermenêutica e a exegese. Portanto, uma definição mais ampla acerca da hermenêutica se faz necessário, segundo Champlin afirma "que esta palavra vem do grego hermeneutikos, que significa interpretação ou arte de interpretar". Da mesma forma, o termo exegese vem do grego, ex, "fora", e agein, "guiar", ou seja, "liderar" ou "explicar".

\section{AS TRÊS FORMAS PRINCIPAIS DE SERMÃO}

As obras tradicionais de homiléticas distinguem em três formas ou tipos de sermões: o sermão temático ou sermão tópico, cujos argumentos resultam do tema, independemente do texto; o sermão textual, cujos argumentos principais são tirados do texto bíblico; e o sermão expositivo, cujos argumentos giram em torno da exposição exegética completa do trecho bíblico em pauta. Nota-se que há vários tipos de sermões e vários meios de classificá-los. Vejamos o que afirma Braga:

Alguns classificam os sermões de acordo com o conteúdo ou assunto; outros, segundo a estrutura; outros ainda quanto ao método psicológico usado no

\footnotetext{
${ }^{5}$ BíBLIA DE ESTUDO PENTECOSTAL. Rio de Janeiro: Editora CPAD, 1995.
}

Revista Pax Domini | Faculdade Boas Novas | v. 2 | p. 16 - 30 | mar. 2017 
momento da apresentação da mensagem. Existem outros métodos, mas talvez o menos complicado seja a classificação em temáticos, textuais e expositivos ${ }^{6}$.

$\mathrm{Na}$ verdade, a pregação bíblica deveria ocupar o lugar primordial nos púlpitos evangélicos, uma vez que a igreja foi organizada e institucionalizada, a sua principal missão é pregar. Infelizmente, a Igreja Contemporânea encontra-se em um período marcado pela superficialidade no púlpito e pelo anti-intelectualismo bíblico - teológico nos bancos da igreja, demonstrando uma necessidade urgente de uma exposição bíblica coerente e eficaz. Como afirma Lopes ${ }^{7}$, "a pregação expositiva é um dos melhores instrumentos para produzir o crescimento sadio da igreja".

\section{CAMINHO OU DESCAMINHO DA PREGAÇÃO EXPOSITIVA NA HISTÓRIA DA ASSEMBLEIA DE DEUS DO BRASIL}

A chegada dos pioneiros das Assembleias de Deus tornou-se um marco na historia do pentecostalismo em solo tupiniquim. Por isso, apresenta-se uma breve referência sobre a origem do movimento pentecostal e a sua influência na evangelização e pregação do pentecostalismo brasileiro.

Daniel Berg nasceu em 19 de abril de 1884 em Vargon, na Suécia. De família batista, era muito pobre, segundo relata sua biografia, sofreu na infância a marginalização de ser "pagão" (só se batizou com 15 anos) numa sociedade que batizava as crianças e, em que, a Igreja Luterana controlava escolas e as igrejas. Aos 18 anos, deixou o seu país com destino aos Estados Unidos. O motivo foi à grande depressão financeira que dominara a Suécia naquele ano. Após sete anos de permanência nos EUA, Daniel Berg se especializa como fundidor, trabalho que seria de suma importância, posteriormente, no Brasil.

No Brasil, Daniel Berg era apenas alfabetizado, nunca assumiu igreja ou qualquer cargo eclesiástico, chega a admitir que pretendia de acordo, com Alencar8 "servir ao Senhor no futuro com sua força física". Alencar destaca a seguinte afirmativa:

\footnotetext{
${ }^{6}$ BRAGA, James. Como preparar mensagens bíblicas. 2. ed. São Paulo: Editora Vida, 2007, p.19.

${ }^{7}$ LOPES, Hernandes dias. A importância da pregação expositiva para o crescimento da igreja. 2. ed. São Paulo: Editora Candeia, 2007, p. 13.

${ }^{8}$ BERG, 1995 apud ALENCAR, 2010, p. 51.
}

Revista Pax Domini | Faculdade Boas Novas | v. 2 | p. 16 - 30 | mar. 2017 
Nas entrevistas com os pastores, quando perguntados por que Daniel Berg nunca assumiu a presidência da Convenção ou de uma igreja, as respostas variaram entre: "ele era muito humilde; era apenas um evangelista, vivia nas ruas e nos trens distribuindo literatura; era um analfabeto, nunca aprendeu a falar português!"'.

Adolph Gunnar Vingren nasceu em 8 de agosto de 1879, em Ostra Husby, Ostergotland, Suécia. Ao contrario de Daniel Berg, fora educado desde sua infância nos ensinamentos cristãos. Porem aos 12 anos de idade desviou-se do evangelho. Segundo narrou em seu diário, "caiu profundamente no pecado até aos 17 anos, quando o Senhor outra vez o chamou". Aos 18 anos, foi batizado nas águas em uma igreja batista, neste mesmo ano, substituiu o seu pai no trabalho da Escola Dominical. Gunnar Vingren fora a exemplo de Berg atraído pela "febre dos Estados Unidos", aonde chegou em 19 de novembro de 1903, depois de 19 dias de viagem, apesar de não falar inglês, conseguiu localizar a casa do seu tio, Carl Vingren.

No fim de Setembro de 1904, foi para Chicago, a fim de começar um curso de quatro anos no seminário teológico sueco dos batistas. Durante os estudos, pregou muitas vezes em diferentes igrejas e lugares. Concluiu os seus estudos em 1909, assumindo o pastorado da Primeira Igreja Batistta em Menominee, de junho de 1909 a fevereiro de 1910.

A experiência de Vingren com o pentecostalismo ocorreu no ano de 1909 na conferencia batista realizado na cidade de Chicago, depois de cinco dias de busca, recebeu o batismo, onde também conheceu Daniel Berg.

No dia 19 de novembro de 1910, os dois missionários suecos desembarcaram no Brasil, na cidade em Belém. Não traziam endereço de alguém que os abrigasse, estavam sem dinheiro, não sabiam falar uma palavra em português, mas estas adversidades não foram suficiente para desanimá-los. Vinham acreditando apenas em uma "visão" dada por Deus. Alencar faz o seguinte comentário sobre a chegada dos missionários suecos em solo tupiniquim:

\footnotetext{
${ }^{9}$ ALENCAR, Gedeon. Assembleia de Deus: origem, implantação e militância (1911-1946). 1. ed. São Paulo: Arte Editorial, 2010, p. 51).
}

Revista Pax Domini | Faculdade Boas Novas | v. 2 | p. 16 - 30 | mar. 2017 
Era, alias, a forma "natural" de se fazer missões no inicio do século a partir da Rua Azuza. As denominações tradicionais já tinham estabelecido organismos de missões, mas o pentecostalismo é apenas um movimento ${ }^{10}$.

Por ser oriundo de uma Igreja Batista na América (as igrejas que aceitavam o avivamento permaneciam com o mesmo nome), procuraram uma igreja batista que tinha os mesmos princípios teológicos das suas respectivas igrejas dos Estados Unidos. Com a convivência com os irmãos batistas, os missionários, a princípio não intencionavam fundar uma nova igreja, queria apenas que os batistas abraçassem as doutrinas pentecostais.

A primeira brasileira a receber o batismo com o Espírito Santo fora Celina de Albuquerque na madrugada de 2 de junho de 1911. Este fenômeno resulta em uma tensão entre os membros da comunidade, pois muitos protestavam contra a nova doutrina. No entanto, Daniel Berg e Gunnar Vingren, com 17 pessoas, expulsos arbitrariamente da Igreja Batista, fundava-se uma nova igreja, com o mesmo nome empregado pelo evangelista Willian Joseph Seymour, Missão Fé Apostólica, mas sem nenhum vínculo com a missão da Rua Azuza em Los Angeles. Conde afirma:

\begin{abstract}
A nova igreja estava livre para evangelizar. E, ousadamente, anunciava a salvação, a cura divina, o batismo com o Espírito Santo e a volta de Jesus Cristo para buscar a sua Igreja. Vivificando cada testemunho e sermão, o Espírito Santo convencia os mais vis pecadores ${ }^{11}$.
\end{abstract}

No ano de 1918, por sugestão de Gunnar Vingren"12, a igreja ganhou o nome de Assembleia de Deus, nome que tinha sido adotado por pentecostais dos EUA, mas destaca-se que a Assembleia de Deus do Brasil, até o momento ainda não tinha vínculos institucionais com os irmãos pentecostais americanos.

\title{
5 O DESENVOLVIMENTO DA MENSAGEM ASSEMBLEIANA
}

Os pentecostais são responsáveis pelas mudanças no cenário religioso, devido a sua atuação em varias camadas da nação brasileira. Seja na política ou na mídia, ou

\footnotetext{
${ }^{10}$ ALENCAR, 2010, p. 50.

${ }^{11}$ CONDE, Emilio. História das Assembleias de Deus no Brasil. 1. ed. Bangu, RJ: CPAD, 2010, p. 33.

12 VINGREN, Ivar. Diário do pioneiro. 1. ed. Bangu, RJ: CPAD, 2010.
}

Revista Pax Domini | Faculdade Boas Novas | v. 2 | p. 16 - 30 | mar. 2017 
mesmo em lugares quase inóspitos como favelas ou presídios, os pentecostais presentes estão. Mariano faz o seguinte comentário:

A expansão do pentecostalismo constitui fenômeno de amplitude mundial, posto que este ramo do cristianismo, formado no inicio do século na America do Norte, vem crescendo aceleradamente em varias sociedades em desenvolvimento do sul do Pacifico, da África, do leste e do sudeste da Ásia. Trata-se de um autêntico processo de globalização ou transnacionalização dessa forma de protestantismo popular ${ }^{13}$.

O pentecostalismo em suas múltiplas frentes denominacionais é, fundamentalmente, formado pelos mais pobres, analfabetos, muitos ex-escravos ainda estavam vivos na época. Hostilizados pelos católicos romanos em sua formação, agora os pentecostais são portadores de uma mensagem que todos podiam ouvir, repetir e da qual podem se apropriar, eles podia até andar com a bíblia para ler e explicar aos demais. Alencar ressalta o seguinte:

Os demais líderes protestantes são cultos, sábios, as igrejas denominacionais são ricas e importantes, mas estão em vantagem? Na visão assembleiana este status é ruim, ou não bíblico. Ser bíblico é ser pobre, perseguido, simples, não culto, pois assim, somente assim, pode-se ter identificação com a igreja dos Atos dos Apóstolos e, mais ainda, com o próprio ministério ${ }^{14}$.

Mediante essa realidade, o conteúdo de suas mensagens era de linguagem simples, mas saturada de grande entusiasmo. O culto era dotado de manifestações sobrenaturais, como curas milagrosas, línguas estranhas e exorcismos. Existia um momento do culto em que todos tinham oportunidade para testemunhar; era a sociabilidade na liturgia, esse momento ocorria antes da ministração da palavra. Araújo alega:

Os cultos pentecostais são bem diferentes dos cultos realizados em algumas igrejas históricas, pois alguns do grupo histórico conservaram suas características europeias e americanas, seus costumes, seus valores e culturas. Os pentecostais, por sua vez, abrasileiraram a liturgia de maneira que ela se tornou peculiar,

\footnotetext{
${ }^{13}$ MARIANO, Ricardo. Neopentecostais: sociologia do novo pentecostalismo no Brasil. São Paulo: Loyola, 1999, p. 9).

${ }^{14}$ ALENCAR, 2010, p. 128.
}

Revista Pax Domini | Faculdade Boas Novas | v. 2 | p. 16 - 30 | mar. 2017 
relevantes e muitas vezes puramente brasileiras. Desde os primórdios dos cultos pentecostais no Brasil, é normal ouvir pessoas criticarem a liturgia pentecostal comparando-a com os rituais da Umbanda e do Candomblé ${ }^{15}$.

A mensagem assembleiana enfatiza a experiência da salvação bem como a experiência do batismo no Espírito Santo. Conde ${ }^{16}$ afirma "que a mensagem pentecostal trazia, em si, o espírito missionário". Os membros tinham oportunidade de participação nos cultos, que por sua natureza, se expressam cantando, gritando, chorando e dançando, com suas alegrias ou tristezas, não eram tratados como expectadores e sim como participantes, valorizados e atuantes. Como alega Rolin 17 "podiam falar, pregar, orar com suas palavras e gestos e dar depoimentos e aclamar o poder de Deus".

A Reforma Protestante do século de XVI enfatizava o sacerdócio de todos os crentes, independente da raça, da cor, da posição diante da sociedade, tem o direito de falar com o "sagrado" sem indulgências imposta pela igreja católica. Nas Assembleias de Deus esta solicitação dos reformadores fora realizado. Os crentes leigos tinham oportunidades de pregarem, não havia necessidade do conhecimento homilético, hermenêutico ou exegese. O essencial é ter fé, com palavras simples corroborar a grandeza de Deus. Araújo afirma:

No pentecostalismo brasileiro, especialmente no âmbito das Assembleias de Deus, em suas primeiras décadas, todos os crentes, tanto homens como mulheres, eram conclamados a serem pregadores do evangelho, em cumprimento da ordem de Jesus em Marcos 16.15, "ide e pregai", independentemente de uma formação bíblica e teológica prévia e do cargo eclesiástico que possuísse. [...] Dezenas de crentes ficaram conhecidos como pregadores, viajando em diferentes partes do país. Por meio do seu trabalho, centenas de igrejas Assembleias de Deus foram fundadas ${ }^{18}$.

Torna-se relevante afirmar que o pentecostalismo não fez opção pelos pobres. Mas, historicamente o movimento comprova ter nascido com os pobres, escolhido pelas minorias que viviam marginalizadas, esquecidas e desprestigiadas pela burguesia, desconfiada dos partidos políticos e difamados pelos irmãos tradicionais. Portanto, o

\footnotetext{
${ }^{15}$ ARAÚJJ, Isael de. Dicionário do Movimento Pentecostal. Bangu, RJ: CPAD, 2007, p. 38.

${ }^{16}$ CONDE, 2010, p. 38.

${ }^{17}$ ROLIM, Francisco Cartaxo. Pentecostais no Brasil: uma análise socio-religiosa. Rio de Janeiro: Vozes, 1985. p. 42.

${ }^{18}$ ARAÚJO, 2007, p. 714.
}

Revista Pax Domini | Faculdade Boas Novas | v. 2 | p. 16 - 30 | mar. 2017 
movimento recebe críticas das mais diversas direções, chegando a ser severamente acusado como meio de escapismo e psicose social, pelo fato de não conter um conteúdo teológico formado. Desta forma, a mensagem assembleiana torna-se importante, porque a linguagem com que essa mensagem foi transmitida foi de fácil percepção e assimilada com facilidade pelos seus receptores.

$\mathrm{Na}$ realidade, o alcance das massas obteve êxito devido à mensagem e as estratégicas proclamadas e executadas pelo pentecostalismo que se identifica e sensibiliza com o sofrimento do povo que estava à margem. Em certo sentido, 0 pentecostalismo se tornou um movimento de resposta às divergências sociais. Inclusive, Alencar faz a seguinte afirmação:

\begin{abstract}
Até porque em 1911, a igreja Católica celebrava missas em latim, as igrejas Luterana e Adventista, cultos em alemão, e a igreja Anglicana e todas as demais denominações protestantes num "teologuês" anglo-saxônico. Periférica, simples e marginal, cresceu entre os pobres. Ela não optou pelos pobres. Ela é uma igreja de pobres. Portanto, na marginalidade. No entanto, esta natureza de pobre e simples sempre foi vista internamente como "marca da escolha divina"19.
\end{abstract}

Não podemos descartar o fenômeno social de expansão territorial conhecido como êxito rural, que provocou o aumento da população das grandes metrópoles com a chegada das famílias que viviam no interior do país. Em menos de 20 anos, o pentecostalismo já se encontrava espalhado em todas as capitais do Brasil.

No entanto, com a partida de Vingren para o Rio de Janeiro, a igreja Assembleia de Deus em Belém ficou sobre a responsabilidade de Samuel Nystron, o responsável direto por instituir o ministério de evangelismo itinerante. Para esse ministério foi designado o pastor José Morais, que deveria servir em tempo integral. Como ratifica Conde:

Em 1927, a Assembleia de Deus em Belém, considerando a falta de pastores e evangelistas, e atendendo ao fato de que muitas igrejas passavam meses seguidos sem visita de obreiros, iniciou-se o que se pode chamar de evangelismo itinerante. Para esse ministério foi designado o pastor José Morais, que deveria servir em tempo integral ${ }^{20}$.

\footnotetext{
${ }^{19}$ ALENCAR, 2007, p. 58.

${ }^{20}$ CONDE, 2008, p. 47.
}

Revista Pax Domini | Faculdade Boas Novas | v. 2 | p. 16 - 30 | mar. 2017 


\section{A IMPORTÂNCIA DA PREGAÇÃO EXPOSITIVA NAS ASSEMBLEIAS DE DEUS NO BRASIL}

A Palavra de Deus é o fator essencial para a transformação espiritual do ser humano. A exposição bíblica conecta o pregador as pessoas, considerando que os corações destas pessoas são transformados quando se deparam com a Palavra de Deus. Segundo a afirmativa de Chapell:

[...] os pregadores expositivos ficam comprometidos a dizer o que Deus diz. Não estamos interessados em propagar nossas opiniões, filosofias ou reflexões especulativas. O interesse do pregador expositivo deve ser a verdade de Deus proclamada de tal maneira que as pessoas possam ver que os conceitos emanam da Escritura e aplicam-se a vida pessoal de cada um ${ }^{21}$.

Diante disso, o Brasil tem experimentado um crescimento quantitativo das igrejas pentecostais. Embora haja o alcance numérico das pessoas, a maioria delas desconhece um ensino fiel e consistente das Sagradas Escrituras. O misticismo ${ }^{22}$ tem prosperado, largamente, no solo brasileiro. Como resultado, temos visto uma busca desequilibradas pela experiência, por prosperidade e curas, mas não admite ser confrontada pela Palavra de Deus. Assim, pregam não a Bíblia, mas os pensamentos enganosos de suas próprias interpretações.

A Bíblia é o livro mais importante da historia e o seu desenvolvimento se deu na própria historia humana. Há livros que tradicionalmente pertencem a um povo, mas a Bíblia pertence a todos os povos, é o livro da humanidade. Lopes acrescenta que "o grande propósito da Bíblia não é acrescentar conhecimento, mas mudar vidas ${ }^{23}$ ( $2 \mathrm{Tm}$ 3:16-17; Rm 1:16; Jo 5:39)". A Bíblia é a revelação divina, sua origem está em Deus e não no homem. O apostolo Paulo escreve: "Toda a Escritura é inspirada por Deus e útil para o ensino, para repreensão, para correção, para a educação na justiça” (2 Tm 3.16) ${ }^{24}$.

O ponto culminante da Reforma Protestante foi a restauração da centralidade das Escrituras. As Escrituras fornecem ao mensageiro o texto bíblico a ser extraído, sem

\footnotetext{
${ }^{21}$ CHAPELL, Bryan. Pregação Cristocêntrica. 2. ed. São Paulo: Cultura Cristã, 2007, p. 23.

${ }^{22}$ Misticismo é a experiência de uma relação imediata e prolongada com a divindade e a maneira em que essa experiência serve de eixo para toda a vida.

${ }^{23}$ LOPES, 2007, p. 76.

${ }^{24}$ BÍBLIA DE ESTUDO PENTECOSTAL, 1995.
}

Revista Pax Domini | Faculdade Boas Novas | v. 2 | p. 16 - 30 | mar. 2017 
impor ideias humanas ao texto. Segundo John Stott ${ }^{25}$ "o oposto da exposição é a imposição, que significa impor ao texto o que ele não contém". Muitas Igrejas no Brasil tem negligenciado o seu compromisso com a supremacia da Escritura, descentralizando a palavra de Deus dos púlpitos.

Os falsos ensinamentos ganham notoriedade a partir do momento que a suficiência da Escritura é substituída por doutrinas errôneas. As igrejas contemporâneas experimentaram crescimento numérico, infelizmente, mudaram a mensagem bíblica para a mensagem centrada no homem. $O$ pragmatismo ${ }^{26}$, não a teologia, tem trilhado o caminho de muitos pregadores. Ao abandonar a sã doutrina, e ajustar aos ensinamentos de acordo com as exigências do mercado, a igreja embarcou numa peregrinação para o pós-modernismo. O evangelho tornou-se um produto comercial, uma fonte de lucro. Eles não analisam a Bíblia em seu contexto histórico e exegético. Diante disso, é interesse mencionar as palavras de Lopes $^{27}$ "não orientam os crentes com a Palavra escrita de Deus, mas mediante revelações subjetivas e extra-bíblicas. Desse modo, os líderes religiosos, algumas vezes, manipulam os crentes".

Uma das possíveis respostas para tal desequilíbrio espiritual seria a ignorância, quanto aos conceitos básicos de uma fé arraigada nas Escrituras. Muitas pessoas dependem dos líderes espirituais, por pensarem que esses líderes são videntes ou iluminados, pois recebem mensagens diretas de Deus, desobedecê-los seria resistir ao próprio Deus. Todavia, quando a igreja se esquece da suficiência da Escritura, ela busca novidade espiritual para encher o espaço vazio. Tendo em vista a real situação das igrejas pentecostais, é preciso urgentemente levar as pessoas a refletirem acerca do caráter de Deus, conforme Ele é relevado nas Sagradas Escrituras. Sendo assim, a valorização do ensino levará a igreja a uma compreensão crescente do caráter de Deus, exortando os cristãos a atentarem à Palavra de Deus, conforme Ele é revelado em sua própria Palavra, "a palavra de Deus alimenta, desenvolve e preserva o entendimento da igreja quanto ao próprio evangelho".

E para construir pontes entre o mundo real e a palavra de Deus com os temas principais da vida, precisamos levar a serio tanto o texto bíblico e o cenário

\footnotetext{
25 STOTT 1999 apud LOPES, 2007, p. 78.

${ }^{26}$ Pragmatismo é o método ou tendência que considera o verdadeiro conceito, ideia, conhecimentos favoráveis ao fim buscado.

${ }^{27}$ Lopes, 2007, p. 82.
}

Revista Pax Domini | Faculdade Boas Novas | v. 2 | p. 16 - 30 | mar. 2017 
contemporâneo. Portanto, esta exploração implica estudo. O teólogo Stott ${ }^{28}$, afirma que "não existe a mínima duvida de que os melhores mestres em qualquer campo do conhecimento são os que permanecem na condição de estudantes a vida inteira".

Posto isso, ninguém chegará a ser um excelente ministro da Palavra de Deus a não ser que seja, em primeiro lugar, um estudioso da mesma. Entretanto, segundo Stott ${ }^{29}$, "precisamos criar tempo para penetrar no texto até entregar os seus tesouros". Em outras palavras, como podemos entregar uma mensagem que se refere ao destino eterno dos homens e mulheres de modo leviano, sem zelo. $O$ interesse pessoal vivifica a atenção. Pregar com firmeza sobre questões pessoais, sobre temas práticos, sobre o presente, você conseguira ouvintes zelosos.

\section{CONSIDERAÇÕES FINAIS}

Considerando as argumentações desenvolvidas ao longo da presente pesquisa acerca da importância da pregação expositiva nas Assembleias de Deus no Brasil, serão apresentadas algumas conclusões obtidas a partir das pesquisas efetuadas. É importante ressaltar que o objetivo deste trabalho não foi chegar a conclusões definitivas, até porque no mercado pentecostal ainda não há materiais com este tema, haja vista o interesse de ampliar o assunto abordado, em um futuro próximo. Entretanto, as considerações finais necessitam ser pontuadas, vamos a elas. Verificou-se através das pesquisas efetuadas, que realmente o sermão expositivo é de suma relevância na arte da pregação, porque permite uma análise teológica, bíblia e sistemáticas de temas doutrinários considerados colunas de sustentação da fé. Não obstante a isso, observou-se que há um caminho ou descaminho da pregação expositiva na história das Assembleias de Deus do Brasil. Sendo assim, a expansão do pentecostalismo segundo os sociólogos atinge as massas marginalizadas e o resultado disso pode ser percebido em pregações superficiais, desprovidas de uma interpretação correta das Escrituras.

\footnotetext{
${ }^{28}$ STOTT, 1999 apud LOPES, Hernandes dias. A importância da pregação expositiva para o crescimento da igreja. 2. ed. São Paulo: Editora Candeia, 2007,p. 191.

${ }^{29}$ STOTT, 2007, p.193.
}

Revista Pax Domini | Faculdade Boas Novas | v. 2 | p. 16 - 30 | mar. 2017 
Finalmente, pode-se afirmar que a pregação expositiva não é apenas um discurso teológico abstrato que não se importa com a situação real da vida ou necessidades visíveis existentes na sociedade. Pelo contrário, propõe uma correta interpretação das Escrituras, contextualizando as realidades específicas. Sendo assim conclui-se que a pregação expositiva busca valores espirituais, harmoniza a ortodoxia e a ortopraxia, ensinando os pilares doutrinários com mais tenacidade, para combater a superficialidade nos púlpitos, o liberalismo teológico e os ensinos místicos. Por isso, que a pregação expositiva torna-se importante para as Assembleias de Deus no Brasil, para dar continuidade do projeto histórico do Reino de Deus, sinalizando-o de forma mais clara possível em nossa sociedade.

\section{REFERENCIAS}

ALENCAR, Gedeon. Assembleia de Deus: origem, implantação e militância (1911-1946). 1. ed. São Paulo: Arte Editorial, 2010.

Protestantismo tupiniquim. 2. ed. São Paulo: Arte Editorial, 2007.

ARAÚJO, Isael de. Dicionário do Movimento Pentecostal. Bangu, RJ: CPAD, 2007.

BERG, Daniel. Enviado por Deus: memórias de Daniel Berg. 1 ed. Bangu, RJ: CPAD, 2010.

BÍBLIA DE ESTUDO PENTECOSTAL. Rio de Janeiro: Editora CPAD, 1995.

BRAGA, James. Como preparar mensagens bíblicas. 2. ed. São Paulo: Editora Vida, 2007.

CHAPELL, Bryan. Pregação Cristocêntrica. 2. ed. São Paulo: Cultura Cristã, 2007.

CONDE, Emilio. História das Assembleias de Deus no Brasil. 1. ed. Bangu, RJ: CPAD, 2010.

LOPES, Hernandes dias. A importância da pregação expositiva para o crescimento da igreja. 2. ed. São Paulo: Editora Candeia, 2007.

MARIANO, Ricardo. Neopentecostais: sociologia do novo pentecostalismo no Brasil. São Paulo: Loyola, 1999.

Revista Pax Domini | Faculdade Boas Novas | v. 2 | p. 16 - 30 | mar. 2017 
OLYOTT, Stuart. Pregação pura e simples. 1. ed. São José dos Campos, SP: Editora Fiel, 2008.

ROLIM, Francisco Cartaxo. Pentecostais no Brasil: uma análise sócio-religiosa. Rio de Janeiro: Vozes, 1985.

SCHULER, Arnaldo. Dicionário Enciclopédico de Teologia. Canoas: Ed. ULBRA, 2002. VINGREN, Ivar. Diário do pioneiro. 1. ed. Bangu, RJ: CPAD, 2010. 